University of Tennessee Health Science Center UTHSC Digital Commons

Spring 4-2019

\title{
Health Information Exchanges in The Community Pharmacy Setting
}

Kenneth D. Sykes

University of Tennessee Health Science Center

Follow this and additional works at: https://dc.uthsc.edu/hiimappliedresearch

Part of the Health and Medical Administration Commons, and the Health Information Technology Commons

\section{Recommended Citation}

Sykes, Kenneth D., "Health Information Exchanges in The Community Pharmacy Setting" (2019). Applied Research Projects. 61. . https://doi.org/10.21007/chp.hiim.0062

https://dc.uthsc.edu/hiimappliedresearch/61

This Research Project is brought to you for free and open access by the Department of Health Informatics and Information Management at UTHSC Digital Commons. It has been accepted for inclusion in Applied Research Projects by an authorized administrator of UTHSC Digital Commons. For more information, please contact jwelch30@uthsc.edu. 


\title{
Health Information Exchanges in The Community Pharmacy Setting
}

\author{
Dr. Kenneth D. Sykes, PharmD., MHIIM, MMHC \\ The University of Tennessee Health Science Center \\ Masters of Health Informatics and Information Management \\ Advisor: Dr. Sajeesh Kumar
}

April 2019 


\section{Acknowledgements}

First, I would like express my sincerest gratitude to the dean and faculty of The University of Tennessee Health Informatics and Information Management department. The direction of Dr. Sajeesh Kumar Kamala Raghavan during this progress has been a blessing. I would also like to thank the faculty of The University of Tennessee College of Pharmacy Department. I am beyond grateful to be selected for the dual degree program! Most importantly, I would like to recognize my family, in particular, my mom, daughter, and fiancé. They have been my biggest support throughout school. Lastly, I would like to thank my brothers of The Omega Psi Phi Fraternity, Inc. Your time, affection, patience, and love has motivated me to stay on course and keep my head high to the finish. Because of this, I am forever grateful. 


\begin{abstract}
The landscape of health care is shifting as new payment models and mandates for health information technology (HIT) rise. There is an unprecedented demand to meet our nation's health care challenges of access, safety, quality, and cost. To meet these demands, the health care industry has recognized a team-based care model which can introduce the collaborative power through health information exchanges (HIEs). Providers like pharmacists, can detect and resolve medication errors, duplications, and omissions by using HIEs. HIEs give pharmacists the entire view of the patient from the bed-side of the hospital to the community pharmacy. However, the implementation of HIE is currently lacking some community pharmacies. With this being said, pharmacy staff has realized the need for HIE, and hopefully, with timely implementation, pharmacists can move from the traditional filling prescriptions role to the clinical services role.
\end{abstract}




\section{Table of Contents}

Chapter 1 - Introduction.............................................. 6

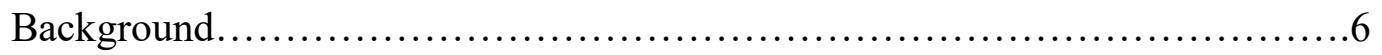

Purpose of Study.....................................................

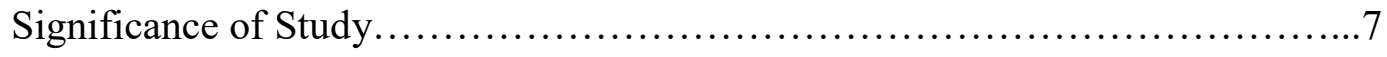

Conceptual Frame of Reference........................................

Definition of Terms.................................................. 8

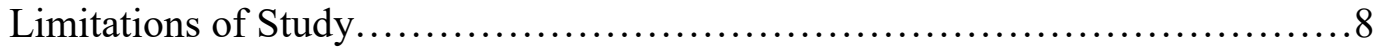

Chapter 2 - Review of Literature................................... $9-13$

Chapter 3 - Methodology............................................ 14

Research Design..................................................14

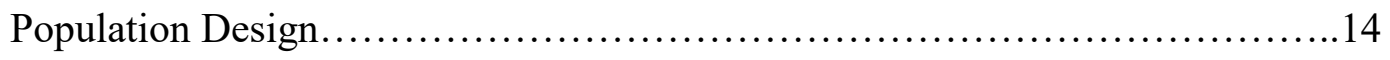

Data Collection........................................................ 14

Data Collection Instrument......................................... 14

Questionnaire............................................................ 15

Chapter 4 - Results................................................. 16

Response Rate of Population......................................... 16

Sample Representativeness........................................... 16

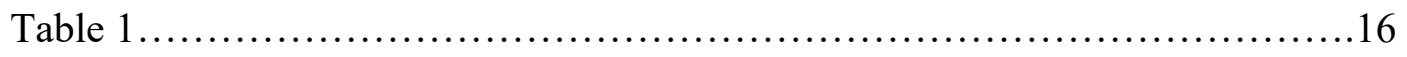

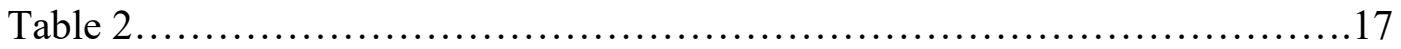




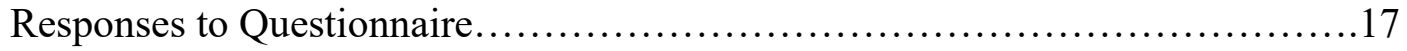

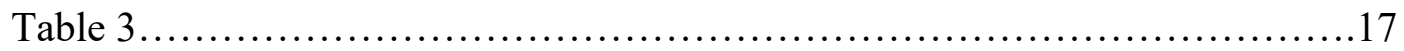

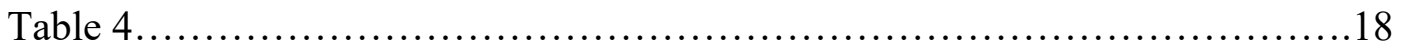

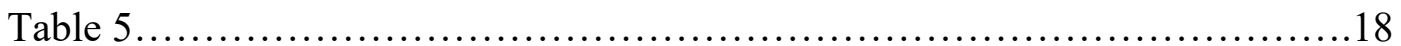

Table of Contents, cont'd

Chapter 5 - Discussion \& Recommendations................................ 19

Summary of Findings.................................................. 19

Implications of Study............................................... 19

Recommendations................................................... 19

Chapter 6 - Conclusion..............................................20

References.......................................................21-22 


\section{Chapter 1 - Introduction}

\section{Background}

Pharmacists serve as patient-oriented professionals who fulfill the healthcare needs of their patients. Within the community setting (i.e., Walgreens, Walmart, CVS, Kroger), pharmacists are the drug experts who serve to educate the public about the proper use, storage, and adverse effects of all medications that are dispensed. However, additional information about the patient is needed so that the pharmacist can be better equipped in making appropriate dosing regimen adjustments. Up to $93 \%$ of patient medical records contain allergy information that is different from the information recorded at the community pharmacy. Pharmacists don't necessarily know when their patients are admitted to the hospital or seen at a clinic. They don't have universal access to patients' labs and past medical histories. And, if patients use multiple pharmacies, community pharmacists most often do not have a complete list of their medications. This patient information is very crucial to patient safety and outcomes where prescribing and dispensing are concerned (Collins, 2016).

Health Information Technology (HIT) is expected to provide integrated electronic health care with interactive exchange among patients, providers, pharmacies, and insurers to result in an increase in overall quality, safety, and efficiency of health care delivery with fewer medical errors, and decreased health care costs (Webster, 2010). For pharmacists to perform their 
functions, they must have the appropriate information. This includes labs, diagnoses, indications of use for medications, the problems that the patient shows, allergy information, and functional assessment information. Pharmacists can help improve patient outcomes in innumerable ways when armed with complete information about their patients (Collins, 2016).

\section{Purpose of Study}

Health Information Exchanges (HIEs) were developed to improve patient outcomes by granting healthcare providers access to patient health information electronically. By having such information, providers like pharmacists, can detect and resolve medication errors, duplications, and omissions. HIEs give pharmacists the entire view of the patient from the bed-side of the hospital to the community pharmacy. This view allows pharmacists to understand the full picture of the patient and better allows them to make the appropriate medication recommendations based on diagnoses, surgical procedures, which this process hasn't been previously made possible. Currently, there is a gap in the literature regarding the process of implementing a HIE into a community pharmacy. The purpose of this study is to analyze the importance of HIE in the community pharmacy setting, the implementation of HIE, and potential barriers.

\section{Significance of this Study}

This study will add new insight to the pharmacy practice because use of health information exchanges provides pharmacists with medication reconciliation services in addition to facilitating the communication of patient health information between healthcare providers. Lastly, community pharmacists can have a positive impact with HIE by detecting and resolving 
medication discrepancies, in addition to, enhancing drug utilization review, medication therapy management, and immunizations.

\section{Conceptual Frame of Reference}

This study is based on the work performed by a student pharmacist attending The University of Tennessee Health Science Center College of Pharmacy. A qualitative approach was used by using questionnaires and interviews with staff pharmacists and pharmacy managers. This model is to identify how pharmacists are aware of the use of HIE and reasons for implementing HIE into practice.

\section{Definition of Terms}

Pharmacist - a health professional who practices in pharmacy, the field that focusing on safe and effective medication use.

Health Information Technology (HIT) - information technology applied to health and health care. It supports health information management across computerized systems and the secure exchange of health information between consumers, providers, and payers.

Health Information Exchange (HIE) - the mobilization of health care information electronically across organizations within a region, community, or hospital system.

\section{Limitations}

There were limitations with conducting this study. The staff pharmacists and pharmacy managers that received the questionnaire and interview are only from one chain pharmacy in the Nashville area. A future study could be conducted to see the comparisons across all chain pharmacies in the Nashville area. In addition, completing the questionnaire was voluntary. 
Lastly, with bias being an issue, work experience and satisfaction of the job played a factor in the questionnaire.

\section{Chapter 2 - Review of Literature}

Our healthcare system is rapidly changing and the healthcare team must be equipped with the proper technology that will assist in delivering optimal patient-centered care. The development of health information exchanges (HIEs) to access patient data across all care settings represents a monumental leap forward in our ability to improve health outcomes. HIEs facilitate the transfer and proliferation of such patient information electronically between healthcare providers and HIEs serve as a translator among various electronic health record (EHR) software languages (Hohmeier 2017). As community pharmacists are the most accessible healthcare provider, they can play an integral role in assisting with drug information questions (Hart 2017). HIE implementation is an increasing interest in healthcare and this literature search attempts to capture pharmacists' utilization, beliefs, and extent to which HIE is used in the community pharmacy setting. 
The literature articles that address the implementation of HIE in the community pharmacy as well as gauging pharmacists' beliefs and utilization were identified by searching free full text articles from electronic databases: PubMed, UTHSC Library, JAPhA, and IJPP. The search was limited to articles published from 2013 to present. The research conducted using relative terms such as HIE, pharmacy HIE, pharmacy EHR, HIE community pharmacy. The 4 articles that were chosen could be applied to the integration and utilization of HIE in the community pharmacy setting.

The primary population focus differed in all the 4 articles. One article primarily focused on patients with public drug insurance who visited emergency departments (ED) in 2 teaching hospitals in Montreal, Quebec (Tamblyn, Poissant, Huang, Winslade, Rochefort, Moraga, Doran, 2013). Another article focused on a list of community pharmacies obtained by the Tennessee Board of Pharmacy (Hart, Hohmeier, 2017). The third article sought to focus on pharmacists who represented a range of pharmacy practice settings and years of experience (Held, Woodall, Hertig, 2014). The last article focuses on a single, independent pharmacy in eastern Tennessee (Hohmeier, 2017).

The literature reviewed had several different methods of researching. No two articles are identical. The first article used a prospective cohort study of patients with multiple ED visits during the study period and only information pertaining to their first visit was collected in the ED chart and the community pharmacy records (Tamblyn, Poissant, Huang, Winslade, Rochefort, Moraga, Doran, 2013). The second article used an IRB exempt cross sectional study of all community pharmacies in Tennessee with a website (Hart, Hohmeier, 2017). The third article used an IRB exempt survey questionnaire consisting of 18 questions assessing respondents' demographics, familiarity with HIE use, and beliefs about HIE (Held, Woodall, Hertig, 2014). 
Another article used mixed methods design. Data collection included a pharmacy and pharmacy technician perceptions survey (Hohmeier, 2017).

Table 1: Comparison of Reviewed Studies

\begin{tabular}{|c|c|c|c|}
\hline Author(s), Year & $\begin{array}{l}\text { Participants, } \\
\text { Survey Method }\end{array}$ & Variables & Results \\
\hline $\begin{array}{l}\text { Tamblyn, } \\
\text { Poissant, } \\
\text { Huang, } \\
\text { Winslade, } \\
\text { Rochefort, } \\
\text { Moraga, } \\
\text { Doran (2013) }\end{array}$ & 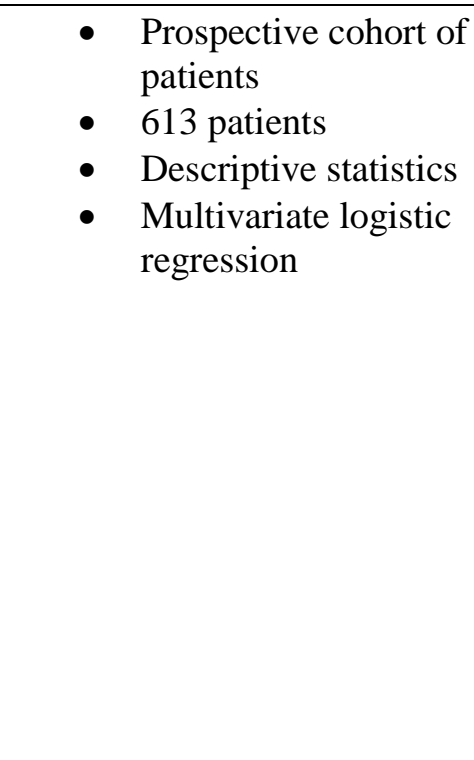 & $\begin{array}{ll}\text { - } & \text { Gender } \\
\text { - } & \text { Age } \\
\text { - } & \text { Medications } \\
\text { - } & \text { Comorbidities }\end{array}$ & $\begin{array}{l}\text { 613 patients participated } \\
\text { (mean age, 63.1 years, } \\
59.2 \% \text { women) Pharmacy } \\
\text { records indicated } 41.5 \% \\
\text { more prescribed medications } \\
\text { than were noted in the ED } \\
\text { chart. } \\
\text { Highest for anticoagulants, } \\
\text { cardiovascular drugs, and } \\
\text { diuretics. } \\
\text { Patients with more than } 12 \\
\text { medications (OR } 2.92,95 \% \\
\text { CI } 1.71 \text { to } 4.97) \text { and more } \\
\text { than one pharmacy (OR } \\
\text { 3.85\%, 95\% CI 1.80 to 6.59) } \\
\text { were more likely to have } \\
\text { omissions in the ED chart }\end{array}$ \\
\hline $\begin{array}{l}\text { Hart, } \\
\text { Hohmeier (2017) }\end{array}$ & $\begin{array}{ll}- & \text { Cross-sectional study } \\
\text { - } & \text { Initial list of } 2568 \\
& \text { pharmacies in TN }\end{array}$ & 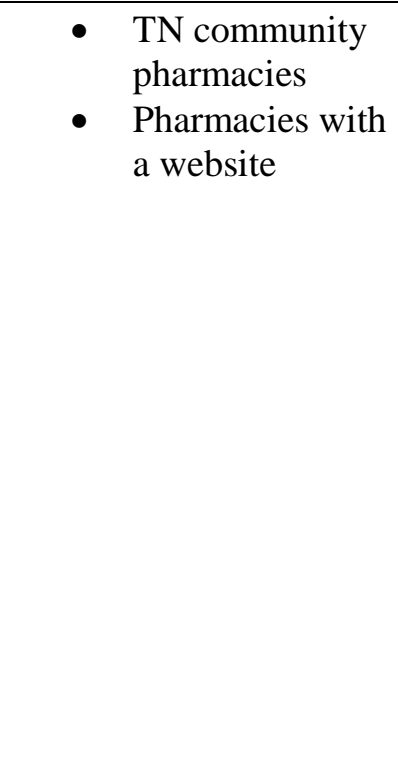 & $\begin{array}{l}\text { - Initial list of } 2568 \\
\text { pharmacies, } 1161 \\
\text { community pharmacies met } \\
\text { criteria which equated to } 169 \\
\text { websites ( } 152 \text { for } \\
\text { independent pharmacies and } \\
17 \text { for chain pharmacies } \\
\text { - Only } 21 \% \text { (n=36) of all } \\
\text { websites listed a drug } \\
\text { information resource } \\
\\
\text { Of those sites providing drug } \\
\text { information, } 50 \%(\mathrm{n}=18) \\
\text { used the drug information } \\
\text { provider: RxWiki }\end{array}$ \\
\hline $\begin{array}{l}\text { Held, } \\
\text { Woodall, } \\
\text { Hertig (2014) }\end{array}$ & $\begin{array}{l}\text { - } \\
\text { - } \text { Qurvey questionnaire } \\
\text { consisted of } 18 \\
\text { questions on } \\
\text { familiarity, } \\
\text { utilization, and } \\
\text { beliefs about HIE }\end{array}$ & $\begin{array}{l}\text { - Indiana } \\
\text { Pharmacists } \\
\text { Active } \\
\text { membership to } \\
\text { Indiana } \\
\text { Pharmacy } \\
\text { Alliance }\end{array}$ & $\begin{array}{l}\text { Response rate was } 19 \% \\
(67 / 358) \\
\text { Pharmacy practice } \\
\text { experience of respondents } \\
\text { ranged from } 0 \text { to } 5 \text { years } \\
(18 \%, \mathrm{n}=2) \text { to more than } 20 \\
\text { years }(61 \%, \mathrm{n}=41)\end{array}$ \\
\hline
\end{tabular}




\begin{tabular}{|c|c|c|c|}
\hline & $\begin{array}{l}\text { Pharmacists with } \\
\text { varying practice } \\
\text { settings and years of } \\
\text { experience }\end{array}$ & $\begin{array}{l}\text { - Up-to-date email } \\
\text { address }\end{array}$ & $\begin{array}{l}\text { - More than one-half }(70 \%) \text { of } \\
\text { respondents practiced in a } \\
\text { hospital setting. } \\
\text { - Many respondents }(75 \%) \\
\text { were familiar with the } \\
\text { concept of HIE } \\
\text { - } 54 \% \text { currently use some type } \\
\text { of HIE }\end{array}$ \\
\hline Hohmeier (2017) & 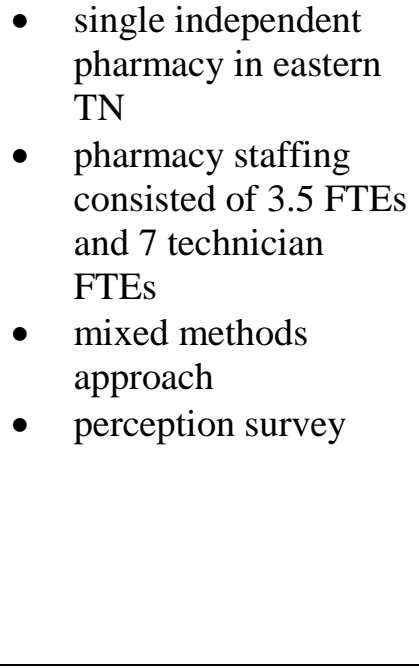 & $\begin{array}{ll}\text { - } & 1 \text { pharmacy } \\
\text { - } & \text { location } \\
\text { - } & \text { independent } \\
& \text { pharmacy vs } \\
\text { chain pharmacy }\end{array}$ & $\begin{array}{l}\text { - } 25 \text { patients qualified for the } \\
\text { medication reconciliation } \\
\text { intervention and data } \\
\text { collection } \\
\text { - All patients }(100 \%) \text { had at } \\
\text { least one discordant } \\
\text { medication } \\
\text { - HIE access was used for } \\
60 \% \text { of patient } \\
\text { - Community pharmacists } \\
\text { were confident in their } \\
\text { abilities to perform } \\
\text { medication reconciliation } \\
\text { and were able to perform the } \\
\text { conciliation utilizing HIE }\end{array}$ \\
\hline
\end{tabular}

In one article, overall, 613 patients met the eligibility criteria. The mean patient age was 63.1 years, $59.2 \%$ were women, and $32.6 \%$ had a health condition that may have created potential communication barriers. In the year before the ED visit, $45.7 \%$ of patients had 4 or more prescribing physicians, and $7.5 \%$ had 4 or more pharmacies. Approximately one quarter (26.1\%) of patients had more than 12 active prescription drug documented at the ED visit, either in the hospital chart or through pharmacy records; $57.3 \%$ used at least one over-the-counter medication, and $14.5 \%$ had at least one illegible drug in the ED chart. There was concordance between the ED chart and pharmacy records for $45.2 \%$ of medications, $41.5 \%$ were only identified in the pharmacy records, and $13.4 \%$ were only in the ED chart. The likelihood of having more drugs documented in pharmacy records than in the ED chart was associated with the number of prescribed drugs, and the number of pharmacies, but not age, sex, hospitalizations, or communication problems (Tamblyn, Poissant, Huang, Winslade, Rochefort, Moraga, Doran, 
2013). Another article focused on community pharmacies in across that state of Tennessee. The initial list from the Board of Pharmacy of Tennessee contained 2568 pharmacies, but only 1161 community pharmacies met criteria which equated to 169 websites evaluated $(n=152$ for independent pharmacies and $n=17$ for chain pharmacies $)$. Only $21 \%(n=36)$ of all websites listed a drug information source. Of the 36, 27 were independent pharmacies and the remaining 9 were chain pharmacies. 50\% $(\mathrm{n}=18)$ used the drug information provider RxWiki while other sites used with rxdrugs.com, FirstDataBank, and RxList (Hart, Hohmeier, 2017). The third article used a survey questionnaire for pharmacists of an Indiana pharmacy organization. The 18-question survey assessed pharmacists' demographics, familiarity with HIE supporting technology, and beliefs about HIT. 67 of the $358(19 \%)$ respondents answered the survey questionnaire. Respondents represented a range of pharmacy practice setting and years of experience. $70 \%$ of the respondents practice in a hospital setting and $6 \%$ were independent community pharmacists. $61 \%$ had over 20 years of pharmacy experience and $18 \%$ have $0-5$ years of pharmacy experience. $52 \%$ were women and $75 \%$ were familiar with the concept of HIE. 54\% of the respondents are currently using HIE supporting technology in practice. All respondents believed that the benefits of HIE outweigh or potentially outweigh the barriers. Most the respondents identified improved coordination of care as the greatest potential benefit of HIE and difficulty implementing and maintaining technology as the greatest potential barrier (Held, Woodall, Hertig, 2014). In the last article, 7 pharmacists and 5 technicians were involved in the project and 10 completed the survey. The majority of pharmacists felt confident in their abilities to perform medication reconciliation with HIE access. Regarding the feasibility of implementing HIE into the community pharmacy workflow, pharmacy perceptions were less positive. Notable barriers identified by pharmacists were reaching the prescribing physician for clarification when needed, 
resolving discrepancies in a timely manner, and interference with other workflow duties

(Hohmeier, 2017).

\section{Chapter 3 - Methodology}

In this section, the reader can understand the research design, the population used, data collection procedures, and the questionnaire used to obtain the data.

\section{Research Design}

The method that was used was the descriptive method by using a questionnaire. The questionnaire contains all open-ended to gain extra insight and further thoughts about the questions asked.

\section{Population Design}


The study was limited to staff pharmacists and pharmacy managers who are employed with Walgreens Pharmacy. Walgreens Pharmacy is the current employer of the researcher. The staff pharmacists and pharmacy managers varied in age, gender, religion, years of experience, and education.

\section{Data Collection}

The questionnaires were sent via in-person to address the reasoning for the questions and to introduce myself to all participants. The participants were given 2 weeks to complete and the questionnaires were collected. All participants responded within the 2 weeks. A brief explanation of the study was sent as a cover letter to each participant to explain the study and how their help would be valuable.

\section{Data Collection Instrument}

The questionnaire consists of 9 open-ended questions focusing on HIE and what staff pharmacists and pharmacy managers view as important for its possible implementation.

\section{Questionnaire}

1. Is HIE currently implemented in your setting?

2. What kind of supporting evidence is needed about the effectiveness of the HIE to get staff on board?

3. What kind of evidence shows you that whether or not the HIE is working in your setting?

4. Is there program that staff and/or stakeholders would rather implement?

5. What kinds of changes do you think you will need to make to the HIE so it will work effectively in your setting? 
6. Who will decide whether changes are needed to the HIE so that it works well in your setting?

7. Do you think it would be possible to pilot the HIE before making it available to everyone?

8. What supports are available to help you implement and use the HIE?

9. Would implementing HIE into your setting be beneficial to your workflow?

\section{Chapter 4 - Results}

Chapter 4 details the final analysis and results from the questionnaire. In this chapter, the response rate, sample representativeness and profile, and the response to the questionnaire are outlined. Tables and figures will be displayed to illustrate the responses from the pharmacy managers and staff pharmacists.

\section{Response Rate of Population}


15 questionnaires were physically sent to Walgreens pharmacies in the Nashville, TN metropolitan area. Each participant, staff pharmacist or pharmacy manager, was given 2 weeks to complete the questionnaire. Each participant responded within the given time frame, therefore, there was a $100 \%$ response rate.

\section{Sample Representativeness}

Of the 15 participants, there were 8 staff pharmacists and 7 pharmacy managers who completed the questionnaire. All 15 participants had at least 4 years of experience. Table 1 illustrates the years of experience among the 15 participants. Of notes, the majority of staff pharmacists and pharmacy managers had 6-10 years of experience. Table 2 shows the ages of the staff pharmacists and pharmacy managers. Age and years of experience had a direct relationship. The older age staff pharmacists and pharmacy managers had also more work experience.

Table 1 - Participants' Years of Experience

\begin{tabular}{|l|l|l|l|}
\hline Years of Experience & $4-6$ years & $6-10$ years & Over 10 years \\
\hline Staff Pharmacist & III & IIII & I \\
\hline Pharmacy Manager & II & III & II \\
\hline
\end{tabular}

Table 2 - Participants' Age

\begin{tabular}{|l|l|l|l|}
\hline Age & $24-30$ years of age & $31-45$ years of age & Over 46 years of age \\
\hline Staff Pharmacist & III & IIII & I \\
\hline Pharmacy Manager & II & III & II \\
\hline
\end{tabular}


Health Information Exchanges in the Community Pharmacy Setting

\section{Responses to Questionnaire}

Table 3 - Implementation of HIE in setting

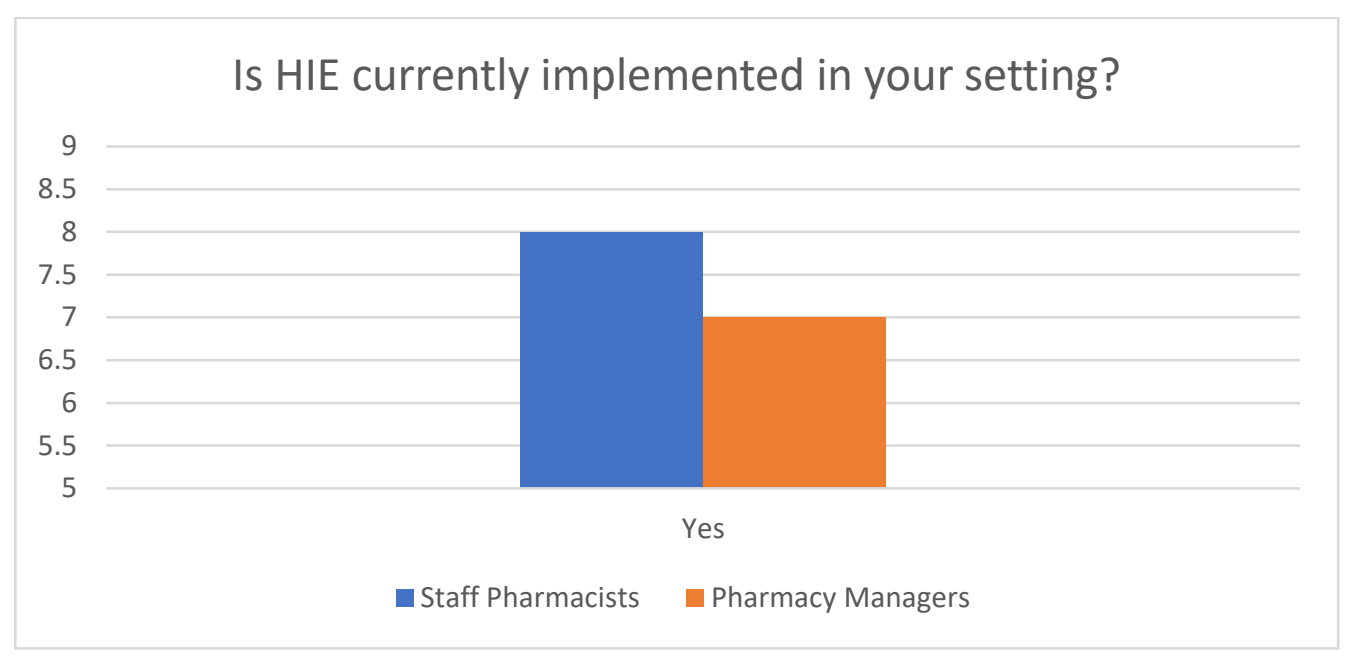

Table 4 - Possible Piloting 
Health Information Exchanges in the Community Pharmacy Setting

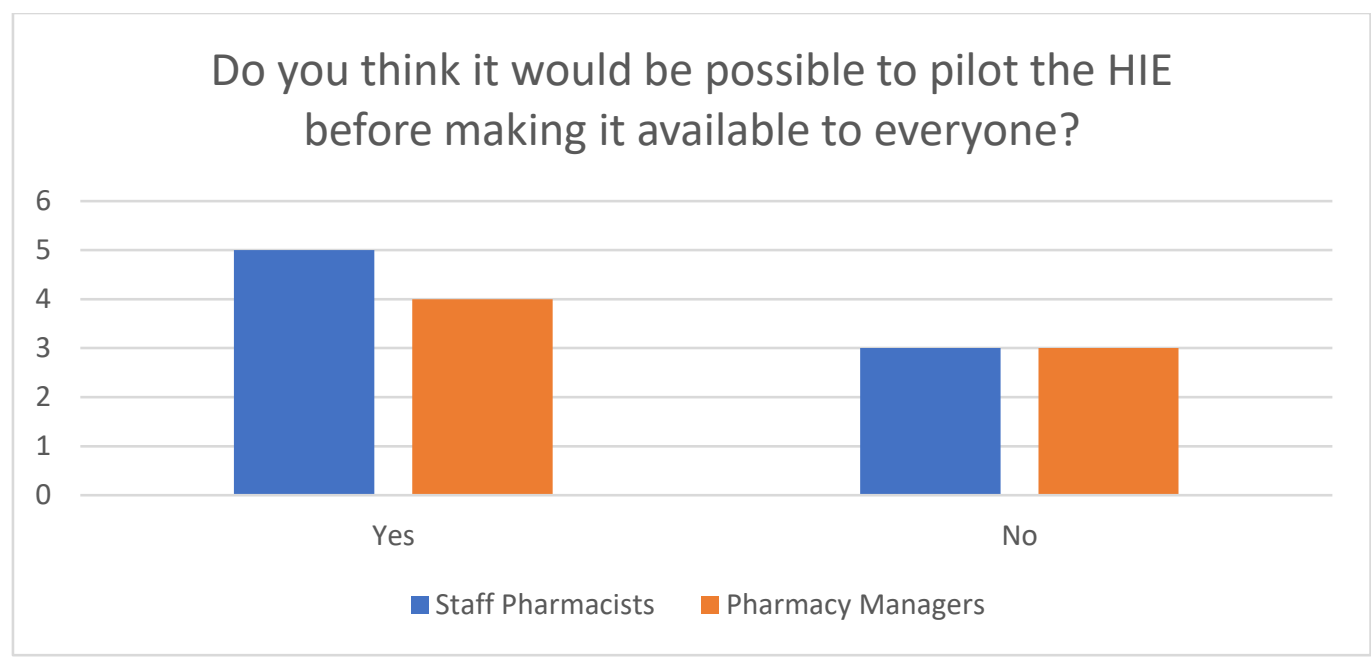

Table 5 - Impact of HIE implementation

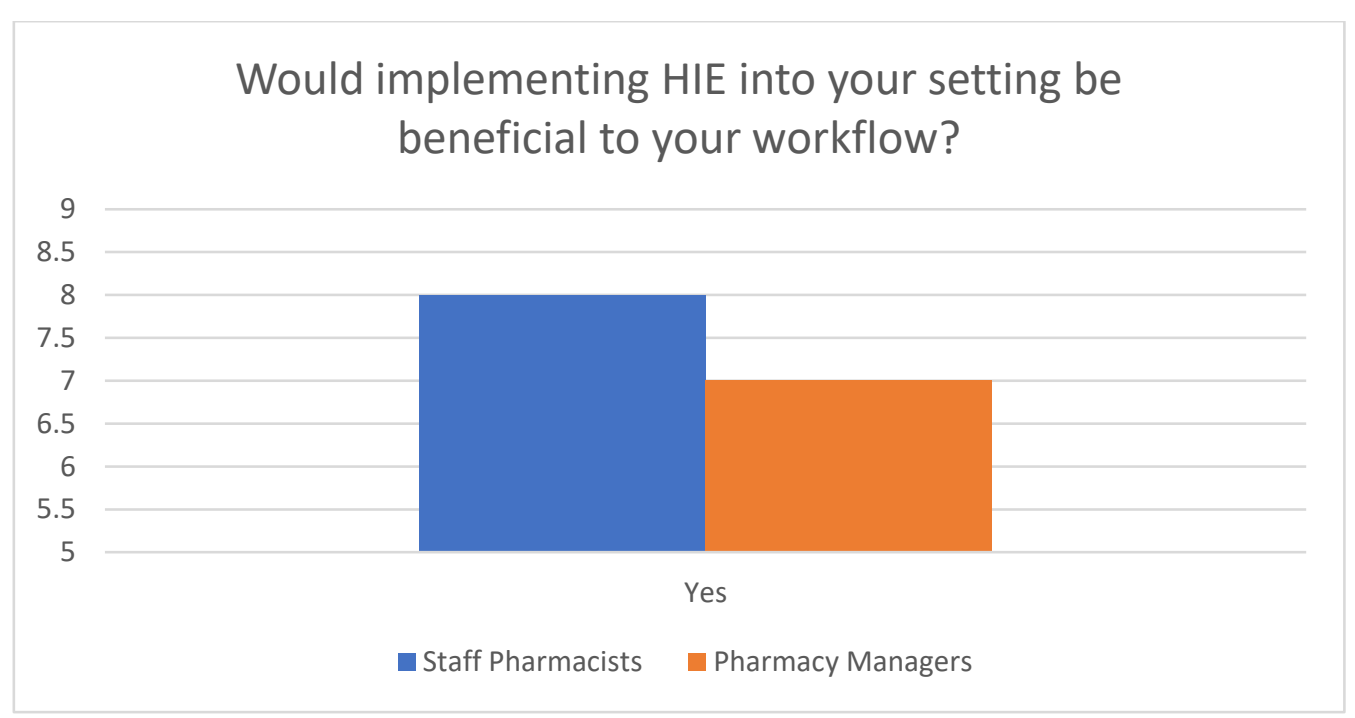




\section{Chapter 5 - Discussion \& Recommendations}

\section{Summary of Findings}

Based on the responses from the questionnaires, both staff pharmacists and pharmacy managers indicated that HIE is not currently used in the practice setting. Other the other hand, both staff pharmacists and pharmacy managers believe that implementing HIE into their setting would be beneficial. Lastly, staff pharmacists and pharmacy managers had different perspectives on piloting HIE before making it available to everyone. 5 staff pharmacists and 4 pharmacy managers believed that piloting HIE would be best before wide spread adoption, whereas 3 staff pharmacists and 3 pharmacy managers were oppose to piloting HIE.

\section{Implications of Study}

The responses from the questionnaire indicate a lack of HIE in the community pharmacy setting and a recognized need for its implementation. Though each participant responded in a timely manner, the sample only represents one chain pharmacy, excluding competitors such as Kroger, CVS, Costco.

\section{Recommendations}

Because of the sample only representing one chain pharmacy, a future study could include other chain pharmacies (Kroger, CVS, Costco). Once chain pharmacies are compared, another study could identify how HIE is used in the particular chain pharmacy and examine costs, workflow efficiency, and evidence of effectiveness. 


\section{Chapter 6 - Conclusion}

With HIE in the community pharmacy setting, pharmacists could have an impact by providing valuable medication history, medication allergy, and vaccination information (Schueth, 2018). Taken a step further, with HIE, pharmacists provide thorough medication therapy management (MTM) sessions. MTM activities can be measured and incented based upon quality measures. Based on this, pharmacists could approach managed care organizations and offer to meet quality threshold for more reimbursement (Schueth, 2018). There is a need to implement HIE in the community pharmacy setting. HIE stands to provide a means of transparent communication between pharmacists and other providers. Improved communication between providers could possibly achieve desired outcomes to help improve adherence, thus decreasing readmissions and increasing quality of care. 


\section{References}

1. Collins, S. Health Information Exchanges: Access in community pharmacies. (2016). Pharmacy Today. 42-43.

2. Webster L, Spiro RF. (2010). A new world for pharmacy. Pharmacy Today;16:32-44.

3. Pharmacy e-Health Information Technology Collaborative. (2017).The Roadmap for Pharmacy Health Information Technology Integration in U.S. Health Care. http://www.pharmacyhit.org/pdfs/11-392_RoadMapFinal_singlepages.pdf.

4. National Transitions of Care Coalition. (2008). Transitions of Care Measures, Paper by the NTOCC Measures Work Group. http://www.ntocc.org/Portals/0/ TransitionsOfCare_Measures.pdf.

5. Surescripts. (2010). The National Progress Report on E-Prescribing and Interoperable Healthcare. http://www.surescripts.com/pdfs/national-progress- report.pdf.

6. Rupp MT, Warholak TL. (2003). Evaluation of e-prescribing in chain community pharmacy: Best-practice recommendations. J Am Pharm Assoc; 48(3):364-370.

7. Health Information Exchange: Taking Pharmacy To The Next Level. http://www.amcp.org/Newsletter.aspx?id=16233.

8. Hart, N., Hohmeier, K. (January, 2017). Availability of drug information of community pharmacy websites in Tennessee. International Journal of Pharmacy Practice, 25, 244247.

9. Held, A.D., Woodall, L. J., Hertig, J. B. (December, 2014). Pharmacists' familiarity, utilization, and beliefs about Health Information Exchange: A survey of pharmacists in 
an Indiana pharmacy organization. Journal of the American Pharmacists Association, 54(6) 625-629.

10. Hohmeier, K., Spivey, C., Boldin, S., Chisholm-Burns, M. (2017). Implementation of a Health Information Exchange into Community Pharmacy Workflow. Journal of the American Pharmacists Association.

11. Tamblyn, R., Poissant, L., Huang, A., et al. (2014). Estimating the information gap between emergency department records of community medication compared to on-line access to the community-based pharmacy records. Journal of American Medical Informatics Association. 21, 391-398. 